\title{
Difficult airway leading to carbon dioxide narcosis in a case of fixed cervical spine
}

\author{
Rahul Yadav, Mihir P. Pandia, Parmod K. Bithal, Sachidanand J. Bharati, Indu Kapoor
}

\begin{abstract}
Inability to secure the airway of a patient after induction of anaesthesia may lead to serious consequences including permanent brain damage and even death. Hypoxia is quite common in difficult intubations especially when it is difficult to ventilate the patient. However, carbon dioxide retention severe enough to cause carbon dioxide narcosis and delayed recovery is a rare occurrence. Here, we report a case of a craniovertebral junction anomaly where inadequate ventilation after induction of anaesthesia resulted in carbon dioxide narcosis and delayed awakening. A 54-year-old, American Society of Anesthesiologists II female patient weighing $70 \mathrm{~kg}$ with a diagnosis of craniovertebral junction was scheduled for implant removal for dislodged occipital screw. Fibreoptic intubation was attempted after induction of anaesthesia and muscle paralysis. Even after multiple attempts, intubation could not be done and ventilation by face mask became difficult. Though oxygen saturation could be maintained with the insertion of a laryngeal mask airway (LMA), ventilation was not adequate. The patient remained unresponsive long after discontinuation of anaesthetic agent and reversal of muscle paralysis. Subsequent blood gas analysis showed severe carbon dioxide retention and respiratory acidosis. Patient was given assist control mechanical ventilation through LMA. LMA was removed after improvement in sensorium and the blood gas picture.
\end{abstract}

Key words: Carbon dioxide, delayed recovery, difficult airway, narcosis, respiratory acidosis

\section{INTRODUCTION}

Inability to secure the airway of a patient after induction of anaesthesia may lead to serious complications including permanent brain damage and even death. Inadequate ventilation during airway management causes both hypoxia and hypercarbia. Hypercarbia is known to cause alterations in the level of consciousness ranging from anxiety to coma, depending on the rapidity and severity of development. ${ }^{[1-4]}$ Here, we report a case of a craniovertebral junction anomaly where inadequate

Department of Neuroanaesthesia, All India Institute of Medical Sciences, New Delhi, India

\section{Address for correspondence:}

Dr. Mihir Prakash Pandia, Department of Neuroanaesthesia, All India Institute of Medical Sciences, New Delhi - 110 029, India.

E-mail: pandiamihir@gmail.com

\begin{tabular}{|l|l|}
\hline \multicolumn{2}{|c|}{ Access this article online } \\
\hline Quick Response Code: & Website: \\
\hline & www.jnaccjournal.org \\
\cline { 2 - 2 } & \\
\hline
\end{tabular}

ventilation after induction of anaesthesia resulted in carbon dioxide narcosis and delayed awakening.

\section{CASE REPORT}

A 54-year-old, American Society of Anesthesiologists II female patient weighing $70 \mathrm{~kg}$ with a diagnosis of craniovertebral junction anomaly was scheduled for implant removal for dislodged occipital screw. She had undergone transoral odontoidectomy and posterior fixation with titanium polyaxial lateral mass screws for nonreducible atlanto-axial dislocation with basilar invagination, 3 years ago at our institute. During her previous surgery, fibreoptic tracheal intubation using a $7.0 \mathrm{~mm}$ cuffed orotracheal tube (was done) under general anaesthesia. The intraoperative and postoperative periods were uneventful.

This is an open access article distributed under the terms of the Creative Commons Attribution-NonCommercial-ShareAlike 3.0 License, which allows others to remix, tweak, and build upon the work non-commercially, as long as the author is credited and the new creations are licensed under the identical terms.

For reprints contact: reprints@medknow.com

How to cite this article: Yadav R, Pandia MP, Bithal PK, Bharati SJ, Kapoor I. Difficult airway leading to carbon dioxide narcosis in a case of fixed cervical spine. J Neuroanaesthesiol Crit Care 2016;3:46-8. 
Except for bilateral lower limb weakness (grade 4/5), the patient had no other systemic medical illness. Magnetic resonance imaging scan of craniovertebral junction revealed occipitocervical fusion with the implant in situ and loose occipital screws. Preoperative investigations including electrocardiogram (ECG) and chest X-ray were normal. Her airway assessment showed a Mallampati grade 4 views with restricted neck movements. Since she refused to undergo awake fibreoptic intubation, fibreoptic intubation under general anaesthesia was planned. She was premedicated with glycopyrrolate $0.2 \mathrm{mg}$ intramuscularly, $1 \mathrm{~h}$ before surgery. After attaching routine monitors (pulse oximeter, ECG, noninvasive blood pressure) and preoxygenation for $3 \mathrm{~min}$, anaesthesia was induced with fentanyl $150 \mu \mathrm{g}$ and propofol $150 \mathrm{mg}$. After ensuring satisfactory mask ventilation, muscle relaxation was achieved with $70 \mathrm{mg}$ rocuronium. Orotracheal intubation with size $7.0 \mathrm{~mm}$ tube with fibreoptic laryngoscopy was attempted after $2 \mathrm{~min}$ of rocuronium administration. Though the glottic opening could be visualised, tracheal intubation was not successful even after repeated attempts by experienced anaesthesiologists. It was realised that because of the large size of the tongue, the oropharyngeal space was small and obstructing the passage of the tube. In between the attempts of fibreoptic laryngoscopy, bag, and mask ventilation were successful. $\mathrm{ETCO}_{2}$ values remained between $30 \mathrm{mmHg}$ and $35 \mathrm{mmHg}$ during mask ventilation. After 5 attempts of fibreoptic intubation, mask ventilation started becoming difficult. In spite of the best fitting mask, jaw thrust, use of both hands for holding the mask and insertion of Guedel's airway, ventilation was inadequate with poor chest expansion. Despite unsatisfactory mask ventilation, however, the patient maintained her $\mathrm{SpO}_{2}$ at $90-91 \%$. During this period the patient was ventilated with $100 \%$ oxygen in sevoflurane $2-3 \%$ inspired concentration. A size 4 laryngeal mask airway (LMA) was inserted which improved lung ventilation to a certain extent and increased $\mathrm{SpO}_{2} 95 \%$, but the chest expansion was not very good. We did not get a stable capnogram waveform and the $\mathrm{ETCO}_{2}$ value fluctuated between $20 \mathrm{mmHg}$ and $40 \mathrm{mmHg}$. To avoid awareness, intermittent boluses of $20 \mathrm{mg}$ propofol were given. In view of a cannot intubate and difficult to ventilate situation, it was decided to defer the surgery and awaken the patient.

Muscle relaxant was not repeated after the initial intubating dose. By then $90 \mathrm{~min}$ had elapsed since the administration of rocuronium and the patient was showing sign of the return of spontaneous respiratory efforts. The residual effect of muscle relaxant was reversed with administration of neostigmine and glycopyrrolate. Patient's spontaneous respiratory efforts returned to normal. However, she was not responding to verbal commands. The patient remained unresponsive even though last bolus of propofol was administered $30 \mathrm{~min}$ ago, and the monitor showed zero end-tidal expired tension of sevoflurane. When the patient started to open eyes to a painful stimulus, her pupils were normal in size and she was reacting to light. Train of four monitoring revealed all four twitches of equal height. To antagonize the unlikely persistent action of fentanyl, naloxone $1 \mathrm{mg}$ was given, without any benefit. At this stage, an arterial blood gas analysis (ABG) showed severe respiratory acidosis with hypercarbia ( $\mathrm{pH}$ 6.923, $\mathrm{PaCO}_{2} 154 \mathrm{mmHg}, \mathrm{PaO}_{2} 101 \mathrm{mmHg}$ ). Repeat ABG done after $30 \mathrm{~min}$, had improvement in respiratory acidosis (pH 7.042, $\mathrm{PaCO}_{2} 101 \mathrm{mmHg}, \mathrm{PaO}_{2} 208 \mathrm{mmHg}$ ). Patient was shifted to ICU with LMA in situ and kept on assist control mechanical ventilation. Significant improvement in sensorium and blood gas picture ( $\mathrm{pH} 7.32, \mathrm{PaCO}_{2} 50 \mathrm{mmHg}, \mathrm{PaO}_{2} 251 \mathrm{mmHg}$ ) was seen after $30 \mathrm{~min}$ of assist-control ventilation. LMA was removed over the next $15 \mathrm{~min}$ when the patient became fully awake.

She underwent the surgical procedure 5 days later and on this occasion awake fibreoptic intubation was done using a $7.0 \mathrm{~mm}$ cuffed endotracheal tube (oral). The patient was counseled and she gave her consent for awake fibreoptic aided intubation. The intra operative and subsequent postoperative course remained uneventful and the patient was discharged home on the $4^{\text {th }}$ postoperative day.

\section{DISCUSSION}

Delayed recovery from anaesthesia in our patient occurred due to carbon dioxide narcosis resulting from an inadequate mask ventilation during the airway management. The anaesthetic agents had been stopped long before the attempt was made to awaken the patient from anaesthesia. There was no electrolyte abnormality and patient had no other systemic illness, which could have contributed in delayed awakening. Although the patient's temperature was on the lower side $\left(35^{\circ} \mathrm{C}\right)$, the hypothermia was only mild which would not interfere with recovery from anaesthesia. The patient had received only one bolus of 150 mcg fentanyl at the time of induction, which was unlikely cause of delay in recovery. Moreover, naloxone administration did not speed up recovery. Inadequate reversal of residual muscle paralysis was also ruled out with the presence of all four twitches of equal height on the TOF monitor. The patient developed $\mathrm{CO}_{2}$ narcosis because of inadequate mask ventilation compounded by periods of apnoea while attempting fibreoptic laryngoscopy. It is recommended to administer suxamethonium in the presence of anticipated difficult airway. However, the presence of preexisting muscle weakness deterred us from using suxamethonium. Though we ensured the ease 
of mask ventilation before giving rocuronium, ventilation became difficult progressively because of the pharyngeal trauma resulting from airway insertion and repeated fibreoptic laryngoscopy. Pooling of oral secretions and blood also aggravated the difficulty in ventilation. Even though oxygenation was maintained with ventilation using LMA, ventilation was not adequate. Distention of stomach due to gastric insufflations during the difficult mask ventilation and subsequent tenting of the diaphragm also hampered the excursion of chest wall further reducing washout of carbon dioxide. The oxygen saturation of the patient was maintained satisfactorily in spite of poor chest excursions. We assume that the absence of any pulmonary pathology and ventilation with $100 \%$ oxygen prevented hypoxaemia during the phase of inadequate ventilation.

Retention of carbon dioxide due to inadequate ventilation is commonly seen in the perioperative setting, but severe hypercarbia resulting from difficult intubation causing carbon dioxide narcosis and stuperous or comatose condition is a rare event in the perioperative settings. Primary carbon dioxide narcosis severe enough to alter consciousness level occurs when the $\mathrm{PaCO}_{2}$ level exceeds $100 \mathrm{mmHg} \cdot{ }^{[5]}$ Moderate elevation of $\mathrm{PaCO}_{2}$ commonly causes anxiety, agitation, and signs of increased sympathetic nervous system activity..$^{[5]}$

Yoshida et al. have reported a case of occurrence of sudden EEG depression and low bispectral index (BIS) value due to hypercarbia in a patient who was undergoing laparoscopic surgery ${ }^{[6]}$ In case of inadvertent injection of a muscle relaxant before induction of anaesthesia, a 45-year-female patient developed carbon dioxide narcosis and had a BIS value between 35 and 40 . The $\mathrm{PaCO}_{2}$ of the patient was $130 \mathrm{mmHg} .{ }^{[7]}$

Our case emphasises that maintenance of oxygen saturation during difficult intubation and difficult mask ventilation may give a false assurance of adequate ventilation, more so if $100 \%$ oxygen is being administered. Oxygen saturation of the patient may not fall in the initial stage if the residual functional capacity of the patient is good and decreased consumption of oxygen under general anaesthesia. ABG analysis should be checked to rule out severe hypercarbia during prolonged periods of difficult mask ventilation, especially if the patient is unresponsive to commands after ruling out other causes. Hypercarbia and carbon dioxide narcosis should always be suspected as a possible cause of delayed awakening after prolonged difficult mask ventilation.

\section{Financial support and sponsorship}

Nil.

\section{Conflicts of interest}

There are no conflicts of interest.

\section{REFERENCES}

1. Miller A, Bader RA, Bader ME. The neurologic syndrome due to marked hypercapnia, with papilledema. Am J Med 1962;33:309-18.

2. Sieker HO, Hickam JB. Carbon dioxide intoxication: The clinical syndrome, its etiology and management with particular reference to the use of mechanical respirators. Medicine (Baltimore) 1956;35:389-423.

3. Dulfano MJ, Ishikawa S. Hypercapnia: Mental changes and extrapulmonary complication. An expanded concept of the "CO-2 intoxication" syndrome. Ann Intern Med 1965;63:829-41.

4. McQuarrie DG. A kinetic concept of carbon dioxide narcosis. Ann Thorac Surg 1967;4:205-17.

5. Mecca RS. Coma and delayed emergence. In: Lobato EB, Graventein N, Kirby RR, editors. Complications in Anesthesiology. Philadelphia, USA: Lippinoct Williams and Wilkins; 2008. p. 351-64.

6. Yoshida H, Kushikata T, Kabara S, Takase H, Ishihara H, Hirota K. Flat electroencephalogram caused by carbon dioxide pneumoperitoneum. Anesth Analg 2007;105:1749-52.

7. Lee YW, Chang CC. The bispectral index in a patient with carbon dioxide narcosis. Anaesth Intensive Care 2007;35:453-4. 